\title{
Retirement of Mrs Ann Scott MA: editorial secretary
}

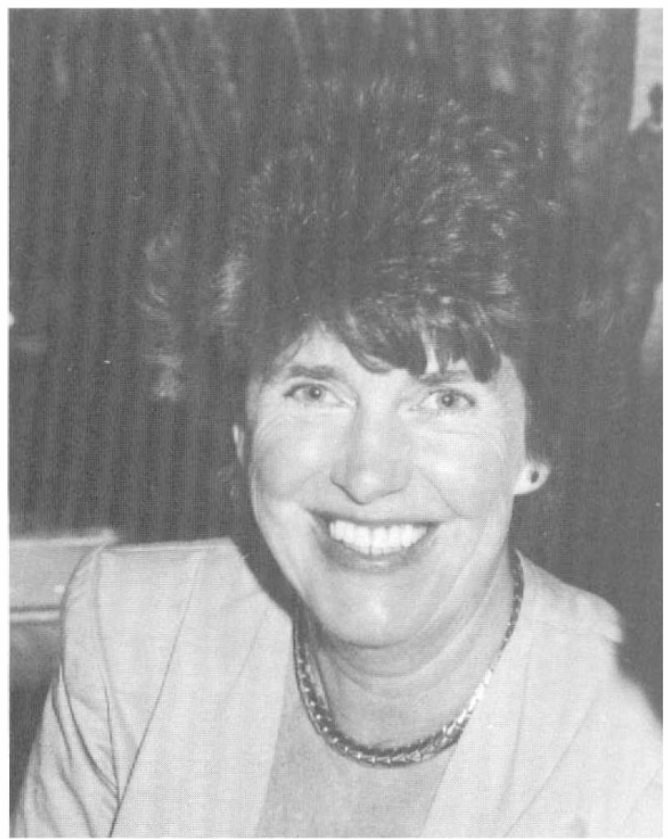

I have been very fortunate in having had Ann Scott as my editorial secretary for the past 8 years. Previously a secretary in the Department of General Practice at the University of Edinburgh, and subsequently in the Departments of Medical Radiology and of Clinical Surgery at the Royal Infirmary of Edinburgh, Mrs Scott became the journal secretary of Paraplegia in 1985. She is a delightful person, industrious, full of good humour, and adaptable to the important changing circumstances of Paraplegia. This international journal of the spinal cord has increased in size and in frequency of publication, being now published monthly. Ann has shown a real interest in the development of our prestigious journal and has been an excellent communicator with the publishers, authors of scientific papers and with referees.

Mrs Scott has now decided to retire from work, to enable her to spend more time with her family, and to have freedom 'to travel the world' with her husband-something that she has looked forward to and will enjoy.

I know that all concerned with Paraplegia and the International Medical Society of Paraplegia will wish her well in her retirement and will join me in thanking her for her practical, dedicated assistance as journal secretary.

Phillip Harris Editor, Paraplegia 